\title{
ENTREPRENEURIAL COGNITIONS: LINKING WILLINGNESS AND ABILITY EXPERT SCRIPTS TO SELF-EFFICACY AND NEW VENTURE CREATION DECISIONS
}

\author{
BORIS URBAN \\ Department of Entrepreneurship \\ University of Johannesburg \\ South Africa \\ Correspondence to: Boris Urban \\ e-mail:borisu@uj.ac.za
}

\begin{abstract}
In bringing the concept of expert scripts to bear upon the venture creation decision and following a script-scenario construction model the existence and degree of mastery of scripts are inferred from a selection of items consisting of paired script recognition and distracter cues. These cognition cues are then linked to motivation, operationalised with the general self-efficacy construct. Individuals with varying demographics who met qualifying criteria from an unrestricted range of businesses and industries $(n=161)$ were surveyed. Moderate support was found to consistently recognise and select statements that evidence expert entrepreneurial scripts. Associations with self-efficacy were modest, suggesting weak links between entrepreneurial cognition and motivation.
\end{abstract}

Keywords: entrepreneurial mindset, motivations, intentions, cultural, individual

Based on the recent application of ideas and concepts from cognitive sciences and how these have gained currency within entrepreneurship research (Amanjee, Crous \& Crafford, 2006; Baron, 2004; Mitchell, Busenitz, Lant, McDougall, Morse \& Smith, 2002), the people side of entrepreneurship is again being revisited. Essentially the entrepreneurial cognitions perspective allows researchers to help understand how entrepreneurs think and why they do some of the things they do (Mitchell, Busenitz et al., 2002, p. 96). The central premise of the cognitive perspective is that entrepreneurial behaviour emerges as a result of the entrepreneur's underlying cognitions.

Entrepreneurial cognition research allows for the articulation of a theoretically rigorous and empirically testable approach that systematically explains the role of the individual in the entrepreneurial process. Building on the conceptual foundations of understanding the role of individuals in venture creation, which is often cited as the rationale for linking entrepreneurship with cognitive theory, it seems logical to assume that entrepreneurship involves a human agency. To be an agent is to intentionally make things happen by one's own actions. The entire entrepreneurial process unfolds because individual entrepreneurs act and are motivated to pursue opportunities (Bandura, 2001, p. 3).

This paper proceeds by first developing a theoretical basis for the specific hypotheses that are subsequently formulated. Next, the research approach, measures and sample are presented, which are then followed by specific analytic methods best suited to testing the hypotheses. Finally the implications of the findings are discussed, the study's limitations are addressed and future research is suggested.

\section{Contextual foundations: Agentic and social cognitive theories}

Research on brain development underscores the influential role that agentic theory plays in shaping the neuronal and functional structure of the brain. By regulating their motivation and activities people produce experiences that form the functional neurological substrate of symbolic, social, psychomotor and other skills. The nature of these experiences is heavily dependent on the types of social and physical environment that people select and construct.
Bandura (2001, pp. 4-8) distinguishes between two major lines of inquiry when investigating agentic theory:

- The microanalysis of the inner workings of the mind in cognitive processing, which is studied disembodied from interpersonal life and self-reflectiveness. Here motivational factors that govern the manner and level of personal engagement are simply taken for granted.

- The second line of theorising focuses on the macroanalytical workings of socially situated factors in human development. Here, human functioning is analysed as socially interdependent, richly contextualised and conditionally orchestrated within the dynamics of various societal subsystems and their complex interplay. The mechanisms linking socio-structural factors to action in this macroanalytical approach remain largely unexplained.

Based on these divergent approaches, it seems as if a comprehensive theory is needed that merges this analytic dualism by integrating personal and social foci of causation within a unified causal structure. Social cognitive theory (SCT) favours the concept of interaction based on triadic reciprocality. Here behaviour, cognitive and other personal factors, and environmental influences all operate interactively as determinants of each other; the term reciprocal refers to mutual action between causal factors (Bandura, 1986, p. 23). However, reciprocal does not mean symmetry in the strength of bidirectional influences. The relative influences exerted by the three sets of interacting factors will vary across different activities, different individuals and different circumstances.

Applied to entrepreneurship, Minniti and Bygrave (2003, p. 37) propose that for each individual, the relative return to entrepreneurship is a function of the set of personal characteristics, the objective socioeconomic circumstances and the rate of entrepreneurship itself. Accordingly, because explanations of behaviour, especially cognitive behaviour, are domain (context) specific, one can expect patterns of entrepreneurial cognition to vary depending on the person's purpose. Fur-ther, in the assessment of person-in-situation, indi-viduals are expected to have a higher degree of self-efficacy when their ability cognitions are more highly developed (Gist \& Mitchell, 1992, p. 187).

With advances in social psychology and specifically in the area of social cognition, this now allows for entrepreneurship 


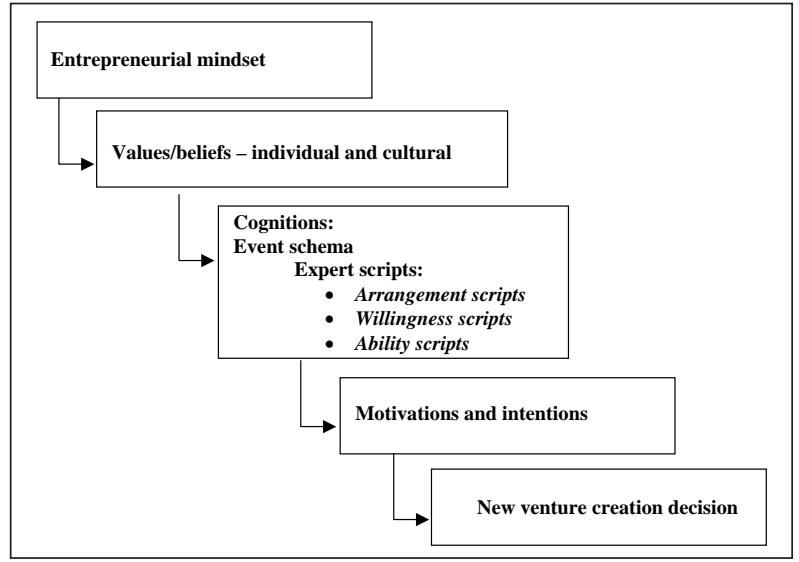

FIGURE 1

Conceptual model of relationships between selected study variables

investigators to address the thinking-doing connection of entrepreneurs more directly. This is in contrast to using proxy variables (demographic differences, need for achievement, risk taking or locus of control) that have produced equivocal results in previous studies (Mitchell et al., 2007, p. 25). The failure of past entrepreneurial personality research to clearly distinguish the unique contributions of entrepreneurs has created a vacuum in the literature (Mitchell et al., 2002, p. 94), with the cognitive perspective providing a useful lens through which to examine entrepreneur-related phenomena.

\section{Interface between entrepreneurship, motivation and cognitions}

The interface between motivational psychology research and entrepreneurship research has remained relatively underdeveloped, despite the interest in motive and its effect on cognition (Mitchell et al., 2007, p. 3). By relying on rigorous methodology and well-established psychological constructs relevant to understanding the characteristics of entrepreneurs, Markman, Balkin and Baron (2002, p. 153) extend the ongoing work of several researchers by seeking to augment and create closer conceptual links between entrepreneurship and cognitions. By focusing on two dimensions previously validated by psychologists but not adequately applied in entrepreneurship research, namely general self-efficacy and regretful thinking, they found that patent inventors tend to have significantly higher self-efficacy and stronger regrets about business opportunities. Moreover, self-efficacy reliably predicts the scope of career options considered, occupational interests, perseverance in difficult fields and personal effectiveness, and it is also related to the pursuit of entrepreneurship; that self-efficacy is a major cognitive variable in the functioning of any entrepreneur is well established (Boyd \& Vozikis, 1994; Krueger \& Brazeal, 1994). Efficacy beliefs are the foundation of human agency, and SCT approaches enhancement of human agency, whether in individual or collective form in terms of enablement (Bandura, 1997, p. 477).

Linking beliefs such as self-efficacy and values to cognitions means that nearly all other mental programmes (such as attitudes and feelings) carry a value component. It is generally concluded in research that more proximal variables, in other words domain-specific beliefs, should have higher explanatory power with regard to specific behaviours than have distal variables such as values; consequently Davidsson and Wiklund's (1997, p. 190) finding that values are more important than beliefs is somewhat surprising. Figure 1 provides a conceptual representation of the interdependent relationships between the selected study variables.

Within the field of entrepreneurship, entrepreneurial cognition scholars have opportunities to bring to the field solid theory and rigorous measures. As Krueger (2007, p. 133) exclaims, "This is more than the usual call for research driven by good theory; given the rich array of tools that cognitive science offers, there is no excuse for ad hoc research studies." Scholars need to incorporate variables such as motivation and affect, since these factors exert tremendous influence on entrepreneurial cognition (Gaglio, 2004, p. 534)

\section{Entrepreneurial cognitions}

The entrepreneurial cognition literature has developed substantially in the area of examination of cognitions relating to entrepreneurial decision-making. Several perspectives can be identified (Baron, 2004; Mitchell, Busenitz et al., 2002; Mitchell, Smith et al., 2002; Mitchell et al., 2007). Refer to Table 1 for the basic questions addressed by the field (relevant cognitive factors are listed under each question).

The idea that cognitions are structured in the minds of individuals and that these knowledge structures act as 'scripts' in that they are the antecedents of decision-making is long established (Read, 1987, p. 289). Cognitions are all the processes by which sensory input is transformed, reduced, elaborated, stored, recovered and used (Neisser, 1967, p. 4).

A definition that builds on previous research defines entrepreneurial cognitions as the "knowledge structures that people use to make assessments, judgments, or decisions involving opportunity evaluation, venture creation, and growth" (Mitchell, Busenitz et al., 2002, p. 97).

TABLE 1

Cognitive factors relevant to issues identified in the field of entrepreneurship research

\begin{tabular}{|c|c|c|}
\hline $\begin{array}{l}\text { WHY DO SOME PERSONS BUT NOT OTHERS } \\
\text { BECOME ENTREPRENEURS? }\end{array}$ & $\begin{array}{l}\text { WHY DO SOME PERSONS BUT NOT OTHERS } \\
\text { RECOGNISE OPPORTUNITIES? }\end{array}$ & $\begin{array}{l}\text { WHY ARE SOME ENTREPRENEURS MORE } \\
\text { SUCCESSFUL THAN OTHERS? }\end{array}$ \\
\hline $\begin{array}{l}\text { Reduced perceptions of risk } \\
\text { (Persons who become entrepreneurs perceive } \\
\text { risks as smaller than other persons do) }\end{array}$ & $\begin{array}{l}\text { Basic perceptual processes } \\
\text { (Persons who recognise opportunities are more } \\
\text { proficient than others at object or pattern recognition) }\end{array}$ & $\begin{array}{l}\text { Counterfactual thinking } \\
\text { (Successful entrepreneurs are better than less } \\
\text { successful ones at using counterfactual thinking } \\
\text { to formulate improved task strategies) }\end{array}$ \\
\hline $\begin{array}{l}\text { Prospect theory } \\
\text { (E.g. persons who become entrepreneurs } \\
\text { overweight small probabilities) }\end{array}$ & $\begin{array}{l}\text { Signal detection theory } \\
\text { (E.g. persons who recognise opportunities are more } \\
\text { proficient at distinguishing 'hits' from 'false alarms') }\end{array}$ & $\begin{array}{l}\text { Processing styles } \\
\text { Systematic vs. heuristic (Successful entrepreneurs } \\
\text { are better at switching between these two } \\
\text { processing styles) }\end{array}$ \\
\hline $\begin{array}{l}\text { Greater susceptibility to various cognitive biases } \\
\text { (E.g. optimistic bias, affect infusion, planning } \\
\text { fallacy and illusion of control) }\end{array}$ & $\begin{array}{l}\text { Regulatory focus theory } \\
\text { (E.g. persons adept at recognising viable } \\
\text { opportunities show a mixed pattern of promotion } \\
\text { and prevention focus) } \\
\text { Entrepreneurial alertness schema (Persons who } \\
\text { recognise opportunities have a more developed } \\
\text { alertness schema) }\end{array}$ & $\begin{array}{l}\text { Reduced susceptibility to certain cognitive biases } \\
\text { (E.g. successful entrepreneurs are more } \\
\text { successful at avoiding biases such as } \\
\text { sunk costs) }\end{array}$ \\
\hline
\end{tabular}

Source: Adopted from Baron (2004, p. 237) and Baron and Ward (2004, p. 554-560). 
Previous research has identified entrepreneurial cognitions to be useful in differentiating between entrepreneurs and nonentrepreneurs (Baron, 2004, p. 221), identifying opportunities (Kruger, 2000, p. 7) and making the venture creation decision (Mitchell et al., 2000, p. 974). Despite researchers' disillusionment with the entrepreneurial trait approach, the fundamental premise that entrepreneurs are members of a homogeneous group that is unique still persists.

Prior research (Mitchell, Smith et al., 2002, p. 102) has found that entrepreneurs, regardless of culture or geographical location, share common experiences in the conceptualisation, start-up and growth of ventures, so it could be deduced that they might share a similar knowledge structure or script regarding new venture formation that novices or even business manager nonentrepreneurs would not share.

Such views are further corroborated when researchers ask whether entrepreneurs have universal cognitions distinct from those of other business people. Although Mitchell, Smith et al. (2002, p. 101) have found that culture does indeed matter in entrepreneurship, their findings reinforce the notion of a universal culture of entrepreneurship, defined by commonality in the centrality of higher-order constructs such as arrangement willingness and ability cognitive scripts (Mitchell, Smith et al., 2000, p. 990).

Through the development of a cognitive model, Busenitz and Lau (1996, p. 27) integrate cognition with social context, cultural values and personal variables. Such model development suggests that some perceptions and beliefs among entrepreneurs transcend cultures.

Individuals in decision-making situations typically draw upon scripts or knowledge structures to make decisions to act Some of these scripts are well developed (expert scripts) while others (novice scripts) are not as fully developed, resulting in information processing-based thinking errors. Specifically, entrepreneurial decisions are the result of motivation and cognitions, the latter including intellect, ability and skills.

In bringing the concept of expert scripts to bear upon the venture creation decision, Mitchell et al. (2000, p. 974) describe cognitions as the mental maps about the contacts, relationships, resources and assets necessary to engage in entrepreneurial activity. They outline the expert scripts necessary for new venture decision-making and then operationalise these expert scripts as follows (Mitchell et al., 2000, p. 987):

- Arrangement scripts are the contacts, relationships, resources and assets necessary to form a new venture. These scripts are the knowledge structures that individuals have about the use of specific arrangements that support their performance and expert-level mastery in a given domain. Typically, individuals making a venture creation decision use appropriate arrangement scripts concerning idea protection, venture networking, accessing resources and venture-specific skills.

- Willingness cognitions are the mental maps that support commitment to venturing and receptivity to the idea of starting a venture. They include actionable thoughts about opportunity seeking (Krueger \& Brazeal, 1994, p. 92), commitment tolerance (Hisrich, 2000, p. 80) and venture opportunity pursuit (McClelland, 1961). Willingness scripts that fo-cus on opportunity seeking are concerned with openness, orientation and drive toward seeking out new situations and possibilities and trying new things. According to Mitchell et al. (2000, p. 988), entrepreneurs are expected to have more highly developed scripts relating to opportunity seeking, commitment tolerance and opportunity pursuit than non-entrepreneurs. Willingness scripts also permit entrepreneurs to experience less risk than non-entrepreneurs because these scripts reduce uncertainty (Krueger, 1993, p. 6). Without willingness scripts, doing/enactment is precluded because prospective venturers will not have the motivation or commitment to make venture creation decisions (Krueger, 1993, p. 7).

- Ability cognitions consist of the knowledge structures or scripts that individuals have to support the capabilities, skills, knowledge, norms and attitudes required to create a venture. At least three scripts relating to ability appear in the entrepre-neurship literature: venture diagnostic scripts, situational knowledge scripts and ability-opportunityfit scripts. Venture diagnostic scripts concern the ability to assess the condition and potential of ventures and to understand the system-atic elements involved in their creation (Krueger, Reilly \& Carsrud, 2000, p. 412). Situational knowledge scripts involve the ability to draw on lessons learned in a variety of ventures and apply those lessons to a specific situation. Finally, ability-opportunity-fit scripts concern the ability to see ways in which customer and venture value can be created in new combinations of people, materials or products. Ability scripts include the capability to assess conditions and potential new ventures, to draw on and apply lessons learned in a variety of ventures and to both see the need for and carry out creation of value by matching opportunity and capability, hence a gain in selfefficacy in making the venture creation decision.

Script enactments, such as making a venture creation decision, require both entry (arrangements) and doing (willingness and ability) scripts in sequence, thus arrangement scripts are thought to have primacy in that they are of concern earlier in the process sequence. Moreover, SCT suggests that interaction between these scripts is integral in expert performance. Therefore arrangement scripts are necessary for enactment of the venture creation decision but not sufficient, since without willingness scripts there may not be enough motivation to use arrangement scripts. Without ability scripts there may be insufficient skill to use arrangement scripts. Willingness scripts without ability scripts may manifest in venture creation decisions, but ventures are short-lived. Thus these different scripts are required collectively but individually insufficient for expert outcomes (Mitchell et al., 2007, p. 14).

Following the approach suggested by Busenitz and Lau (1996, p. 26) and Mitchell et al. (2000, p. 988), the hypotheses examine the relationship between cognitions and self-efficacy, based on a completed venture creation decision. The cognition variables build on previously established cross-cultural models in which the decision to create a new venture, the dependant variable, is influenced by different sets of cognitions treated as the independent variables. The venture creation decision is a relevant and useful dependent variable because it captures decision-making at a point in time when cognitive scripts have had a chance to materialise between intention to venture and venture creation itself. Since both the expert information processing and so-cial cognition literatures suggest that willingness and ability scripts will be related to the venture creation decision, these two sets of cognitions (which exclude arrangement scripts) are related to self-efficacy and examined in the context of completed venture creation decision-making. Since doing presupposes the actor's willingness and ability to carry out the action serving the main goal of the script, for an entrepreneur who has already entered and who has already developed and utilised arrangement cognitions this would mean possessing two further cognitions: those that support willingness and those that apply ability (Mitchell, Smith et al., 2002, p. 94)

Although the hypotheses are couched to imply causality and analysed as such, it is acknowledged that in fact the relationships between the proposed variables are reciprocally causal in nature.

$\mathrm{H} 1$ = respondents who, having completed a venture creation decision, are expected to consistently recognise and select statements that evidence expert entrepreneurial scripts. 
TABLE 2

Frequencies for entrepreneurial cognitions cues: Willingness and ability scripts

\begin{tabular}{|c|c|c|}
\hline VARIABLES & FREQUENCY & PER CENT \\
\hline \multicolumn{3}{|l|}{ Willingness scripts: } \\
\hline \multicolumn{3}{|l|}{ Would you say you are more: } \\
\hline Action oriented; or & 93 & 59 \\
\hline Accuracy oriented? & 66 & 41 \\
\hline \multicolumn{3}{|l|}{ Do you want things: } \\
\hline Open to the possibilities; or & 81 & 51 \\
\hline Settled and decided? & 77 & 49 \\
\hline \multicolumn{3}{|l|}{ I have: } \\
\hline Enormous drive but sometimes ...; or & 81 & 52 \\
\hline High respect for service. & 76 & 48 \\
\hline \multicolumn{3}{|l|}{ Are you more comfortable in: } \\
\hline New situations; or & 76 & 47 \\
\hline Familiar territory? & 85 & 53 \\
\hline \multicolumn{3}{|l|}{ If you had additional money: } \\
\hline Where you have a 'say'; or & 49 & 31 \\
\hline Where it is managed by those you trust. & 111 & 69 \\
\hline \multicolumn{3}{|l|}{ I don't mind: } \\
\hline Being committed to meet a regular ...; or & 122 & 76 \\
\hline Giving a little of the value I create ... & 39 & 24 \\
\hline \multicolumn{3}{|l|}{ I am looking for a: } \\
\hline Place to invest my resources; or & 75 & 47 \\
\hline Better way to manage my resources. & 86 & 53 \\
\hline \multicolumn{3}{|l|}{ When investing in a new venture, I: } \\
\hline Wait too long and miss; or & 65 & 40 \\
\hline Plunge in without enough ... & 96 & 60 \\
\hline \multicolumn{3}{|l|}{ Is it worse to: } \\
\hline Waste your time thinking over ...; or & 43 & 27 \\
\hline Commit time and money to ...? & 118 & 73 \\
\hline
\end{tabular}

\section{Ability scripts:}

If asked to give my time to a new business:

Into my past experience; or

My values.

I feel more confident:

That I know a lot about creating; or

In my overall business sense.

When I see a business opportunity:

How closely it fits my ...; or

Whether I sense that it is a good...

loften:

See ways in which a new product ...; or

Find differences between how I see ...

When confronted with a new venture problem, I:

Recall quite vividly the details; or

Usually figure out what to do.

$83 \quad 52$

When someone describes a problem,

Recognise key features; or

Use my instincts to suggest...

New ventures and small business:

Are distinctly different; or

Have much in common.

I am more:

Aware of many new ventures; or

Familiar with my own affairs.

It is more important to know about:

Creating new ventures; or

Business in general, staying diversified.

New venture success:

Follows a particular script; or

Depends heavily on the pluses.

The new venture stories I recall:

Illustrate principles necessary; or

Are telling commentaries.

\section{8}

83

52

$89 \quad 56$

$69 \quad 44$

$84-53$

76

47

$92 \quad 58$

$68-42$

$73 \quad 45$

$88 \quad 55$

$55 \quad 35$

$104 \quad 65$

$126 \quad 79$

21

Note: Each statement has paired response choices - select one choice. The first one represents expertise or mastery and the second choice does not. Certain statements have been abbreviated for display purposes. For full questions, see Mitchell et al. (2000).
$\mathrm{H} 2$ = entrepreneurial cognitions (willingness and ability scripts) that are positively associated with entrepreneurial motivation (self-efficacy).

\section{RESEARCH DESIGN}

\section{Research approach}

Although the relationship between cognitive scripts and venture creation decisions has been previously documented, this paper builds on the prescriptions of Krueger (2007, p. 123) and extends this relationship to address the two research questions that motivate this study; the interest in motivation, as measured through the self-efficacy construct, and its association with entrepreneurial cognitions and venture creation decisions. Both logic and the literature lead one to expect that dissimilar actors (in a cultural sense) involved in similar undertakings (e.g. entrepreneurship) will have developed a consistent mental knowledge or, effectively, a universal culture of entrepreneurship (Corbett \& Hmieleski, 2007, p. 104).

This study is cross-sectional exploratory research where, due to the multiplicity of interacting influences as postulated in SCT, the same factor might be part of different blends of conditions that have different effects. Since the triadic factors do not operate simultaneously as a holistic entity, it is possible to understand how different segments of a two-way causation operate without trying to study every possible interactant at the same time (Bandura, 1986, p. 25). Hence research aimed at estimating the relative percentage of behavioural variation due to persons or to situations is ill-suited to clarifying the transactional nature of human behaviour, nor is it instructive to read evidence that much of the variation is usually due to the joint effects of personal and situational conditions. Rather, the best-suited methodology will specify conditional probabilities that interacting factors will affect each other's occurrence.

The venture creation decision was measured with a dichotomous variable (coded yes/no) "I have started at least one business that has been in existence for at least two years", which served as the qualifying criterion since only respondents who answered positively were selected to continue with the survey. Experts who have already made a venture decision, when presented with problems within their domain of expertise, are expected to access their cognitive scripts to select response cues consistent with that script. Thus, entrepreneurs who have appropriate willingness and ability cognitions are expected to more consistently recognise and select statements that evidence expert entrepreneurial scripts (Mitchell, Smith et al., 2002, p. 10).

TABLE 3

Chi-square-based measures of association between would you say you are more action oriented or accuracy oriented in terms of entire can do items

\begin{tabular}{lccc}
\hline VARIABLE & $x$ SQUARE & D.F. & SIGNIFICANCE \\
\hline $\begin{array}{l}\text { I will be able to achieve most goals I } \\
\text { have set for myself. }\end{array}$ & 0.060 & 1 & 0.659 \\
$\begin{array}{l}\text { When facing difficult tasks, I am } \\
\text { certain I will accomplish them }\end{array}$ & 0.954 & 1 & 0.240 \\
$\begin{array}{l}\text { In general, I think I can obtain } \\
\text { outcomes that are important. }\end{array}$ & 0.185 & 1 & 0.487 \\
$\begin{array}{l}\text { I believe I can succeed at almost any } \\
\text { endeavour to which I set my mind. }\end{array}$ & 5.893 & 1 & $0.021^{*}$ \\
$\begin{array}{l}\text { I will be able to successfully } \\
\text { overcome many challenges. }\end{array}$ & 0.066 & 1 & 0.518 \\
$\begin{array}{l}\text { I am confident that I can perform } \\
\text { effectively on many different tasks. }\end{array}$ & 0.019 & 1 & 0.553 \\
$\begin{array}{l}\text { Compared to other people, I can } \\
\text { perform most tasks very well. }\end{array}$ & 0.474 & 1 & 0.318 \\
$\begin{array}{l}\text { Even when things are tough, I can } \\
\text { perform quite well. }\end{array}$ & 0.357 & 1 & 0.391 \\
\hline
\end{tabular}

* Significant at the 0.05 level 


\section{Measurement instruments}

Willingness and ability scripts appropriate for venture creation were measured indirectly, following a script-scenario construction model originated by Read (1987, p. 290) and adopted by Mitchell et al. (2000, p. 974). In this approach the existence and degree of mastery of scripts are inferred based on selection by respondents from paired response choices (yes or no); one represents expertise or mastery and one does not. Thus all items consisted of paired script recognition and distracter cues (coded 1 and 0 respectively). The cues are not the cognitive scripts, but cue recognition is evidence that the cognitive scripts exist, and these items are used as formative indicators of the underlying cognitive constructs (Mitchell, Smith et al., 2002, p. 101).

Since formative indicators are independent additive components of a construct, they may not be highly correlated. Consequently it is inappropriate to expect unidimensionality at the construct level (willingness and ability cognitions), and it is inappropriate to assess reliability at the item level with Cronbach's alpha, which is based on inter-item correlation (Mitchell, Smith et al., 2002 , p. 16). Furthermore, since the answer categories are based on dichotomous variables, factor analysis was not possible. Moreover, the dimensions of each formative cognitive construct had been previously tested with principal component factor analysis and support was generally found for the conceptualised dimensions of the cognitive scripts, as established by Mitchell et al. (2000, p. 30). The motivational construct was captured with the revised general efficacy scale (Chen, Gully \& Eden, 2001, p. 72). This instrument consists of eight items relating to can do and measures the respondent's magnitude (yes/no). Chen et al. (2001, p. 72) repeatedly found that additional items added little or nothing to the current measure in terms of reliability and content or predictive validity; the only contribution of adding items beyond the eight included in the scale was to artificially inflate coefficient alpha by adding items that were redundant to items already included and therefore highly intercorrelated with them. Moreover, this instrument was recently tested in the South African context, where the measure was converted into an interval scale and principal component analysis yielded a single factor solution for these eight items with a reliability coefficient alpha of 0.915 (Urban, 2006, p. 6).

\section{Participants and research procedure}

A pretested, self-administered structured survey was administered to 387 potential respondents as part of an experiential exercise by university undergraduate students in the Johannesburg area. Given the difficulty of accessing sampling frames for probability samples in social sciences research (Mitchell, Busenitz et al., 2002, p. 101) a judgemental sampling approach was used to gather data from respondents

TABLE 4

Symmetric measures of association between would you say you are more action oriented or accuracy oriented in terms of the I will be able to achieve most goals item

\begin{tabular}{lcc}
\hline STATISTIC & VALUE & APPROX. SIGNIFICANCE \\
\hline Phi & 0.019 & 0.806 \\
Cramer's V & 0.019 & 0.806 \\
Contingency coefficient & 0.019 & 0.806 \\
\hline
\end{tabular}

TABLE 5

Chi-square-based measures of association between new ventures, small business and entrepreneurship are distinctly different disciplines or have much in common, especially the need for sharp guesswork

\begin{tabular}{lccc}
\hline VARIABLE & $x$ SQUARE & D.F. & SIGNIFICANCE \\
\hline $\begin{array}{l}\text { Even when things are tough, I can } \\
\text { perform quite well. }\end{array}$ & 6.680 & 1 & $0.010^{*}$ \\
$\begin{array}{l}\text { When facing difficult tasks, I am } \\
\text { certain I will accomplish them. }\end{array}$ & 4.429 & 1 & $0.033^{*}$ \\
\hline
\end{tabular}

* Significant at the 0.05 level who met the qualifying criteria from an unrestricted range of businesses, industries and individuals with varying demographics. As previously stated, respondents had to meet the criteria of having individually made the venture creation decision and having started at least one venture that has been in existence for at least for two years. This personal approach resulted in 161 usable surveys.

\section{Analysis of data}

Nonparametric measures of association were employed using cross-classification tables to assess the strength of the relationships between the variables. Various chi-square-based measures tested the strength of the relationship between the test variables, including the Pearson chi-square test, Fisher's exact test, phi, Cramer's V, contingency coefficient and Kendall's tau-b (Cooper \& Schindler, 2001, p. 499). Values were calculated using the asymptotic standard error assuming the null hypothesis (two-sided)

\section{RESULTS}

Consistent with previous research on entrepreneurship and for descriptive purposes, the respondents' age (75\% were in the $20-39$ age bracket), sex ( $72 \%$ were male and $28 \%$ female), level of education completed ( $52 \%$ had completed a diploma or degree) and answer pertaining to parents, friends or relatives who are or had been entrepreneurs (65\% answered "yes" and 35\% "no") were reported. Previous research has found that the likelihood to be a successful entrepreneur is stronger for those who know other entrepreneurs (Douglas \& Shepherd, 2002, p. 83).

Based on the type of data collected - dichotomous questions with yes or no answers - frequency analysis, chi-square tests and symmetric measures were used to analyse the data. Following basic percentage calculations, cross-tabs were conducted for all the entrepreneurial cognition items (20) and compared to the self-efficacy items (8); associations were also made with the control variable relating to parents, friends or relatives who are or had been entrepreneurs.

The frequency and relative percentage for each item measuring willingness and ability scripts in Table 2 may be interpreted as the percentage of expert respondents who when presented with problems within their domain of expertise were expected to access their cognitive scripts to select response cues consistent with that script, in other words select the first cue and not the second cue from each statement. Since there is no statistical method to detect significant differences between the percentages of options selected, this was primarily a subjective analysis where a benchmark of $50 \%$ and greater was used as an indicator for each cue to determine which response was primarily selected. Based on a simple count, $55 \%$ of the items were above the benchmark criterion of $50 \%$, confirming the selection of expert cues by respondents as hypothesised.

Table 3 provides chi-square-based measures of association between the item-measuring cognition scripts - would you say you are more action oriented or accuracy oriented - in terms of the self-efficacy can do items. The observed significance level is more than the testing level $(\mathrm{p}<.05)$ for only one item, "I believe I can succeed at most any endeavour to which I set my mind", with a Pearson chi-square value of 5.893, significant at 0.021 .

Turning to the measures of association for the same variables (refer to Table 4) phi, which is best employed with $2 \times 2$ tables like this one, can range from 0 to +1.0 and attempts to correct $x^{2}$ proportionally to $N$ (Cooper \& Schindler, 2001, p. 554). The phi's coefficient of 0.019 with an approximate significance of 0.806 shows a low relationship between cognitions and motivation Cramer's V, which is a modification of phi for larger tables with a range up to 1.0, and the contingency coefficient, with different upper limit, are similarly reported. 
TABLE 6

Chi-square-based measures of association between I don't mind being committed to meet a regular payroll if it means that I can have a chance at greater financial success or giving a little of the value I create to the company that hired me

\begin{tabular}{lccc}
\hline VARIABLE & $x$ SQUARE & D.F. & SIGNIFICANCE \\
\hline $\begin{array}{l}\text { In general, I think I can obtain } \\
\text { outcomes that are important. }\end{array}$ & 8.151 & 1 & $0.011^{*}$ \\
\hline
\end{tabular}

* Significant at the 0.05 level

\section{TABLE 7}

Chi-square-based measures of association between I am more aware of many new venture situations, some of which succeeded and some of which failed, and why or more familiar with my own affairs but keep up on business in general

\begin{tabular}{lccc}
\hline VARIABLE & $x$ SQUARE & D.F. & SIGNIFICANCE \\
\hline $\begin{array}{l}\text { Even when things are tough, I can } \\
\text { perform quite well. }\end{array}$ & 5.607 & 1 & $0.020^{*}$ \\
$\begin{array}{l}\text { I will be able to successfully overcome } \\
\text { many challenges. }\end{array}$ & 4.535 & 1 & $0.035^{*}$ \\
\hline
\end{tabular}

* Significant at the 0.05 level

TABLE 8

Chi-square-based measures of association between are you more comfortable in new situations or familiar territory

\begin{tabular}{lccc}
\hline VARIABLE & $x$ SQUARE & D.F. & SIGNIFICANCE \\
\hline $\begin{array}{l}\text { Compared to other people, I can } \\
\text { perform most tasks very well. }\end{array}$ & 7.426 & 1 & $0.005^{*}$ \\
$\begin{array}{l}\text { I am confident that I can perform } \\
\text { effectively on many different tasks. }\end{array}$ & 4.182 & 1 & $0.036^{*}$ \\
\hline
\end{tabular}

* Significant at the 0.05 level

\section{TABLE 9}

Chi-square-based measures of association between I recognise key features of the problem quickly and can suggest alternatives from examples I can cite or I use my instincts to suggest questions that should be asked to solve the problem

\begin{tabular}{lccc}
\hline VARIABLE & $x$ SQUARE & D.F. & SIGNIFICANCE \\
\hline $\begin{array}{l}\text { I am confident that I can perform } \\
\text { effectively on many different tasks }\end{array}$ & 4.248 & 1 & $0.016^{*}$ \\
\hline
\end{tabular}

* Significant at the 0.05 level

TABLE 10

Chi-square-based measures of association between is it worse to waste your time thinking over an opportunity or commit time and money to a cause that may not succeed

\begin{tabular}{lccc}
\hline VARIABLE & $x$ SQUARE & D.F. & SIGNIFICANCE \\
\hline $\begin{array}{l}\text { Compared to other people, I can } \\
\text { perform most tasks very well. }\end{array}$ & 3.762 & 1 & $0.048^{*}$ \\
\hline
\end{tabular}

* Significant at the 0.05 level

TABLE 11

Chi-square-based measure of association between new venture success follows a particular script or depends heavily on the pluses and minuses in a given situation

\begin{tabular}{lccc}
\hline VARIABLE & $x$ SQUARE & D.F. & SIGNIFICANCE \\
\hline $\begin{array}{l}\text { Do you have parents, friends or } \\
\text { relatives who are or had ... }\end{array}$ & 4.402 & 1 & $0.028^{*}$ \\
$\begin{array}{l}\text { Even when things are tough, I can } \\
\text { perform quite well. }\end{array}$ & 4.406 & 1 & $0.041^{*}$ \\
\hline
\end{tabular}

* Significant at the 0.05 level

TABLE 12

Chi-square-based measures of association between I don't mind being committed to meet a regular payroll if it means that I can have a chance at greater financial success or giving a little of the value I create to the company that hired me

\begin{tabular}{lccc}
\hline VARIABLE & $x$ SQUARE & D.F. & SIGNIFICANCE \\
\hline $\begin{array}{l}\text { Do you have parents, friends or } \\
\text { relatives who are or had } \ldots\end{array}$ & 3.618 & 1 & $0.042^{*}$ \\
\hline
\end{tabular}

* Significant at the 0.05 level
Similarly, tables 5 to 12 indicate chi-square-based measures with only the significant associations between the cognition scripts and the specific self-efficacy items reported. Specifically, the highest Pearson chi-square value is 8.151 for the selfefficacy item "In general, I think I can obtain outcomes that are important to me" associated with the willingness script "I don't mind being committed to meet a regular payroll if it means I have chance at greater financial success". Another pertinent observation is that most of the self-efficacy items are related to only a few of the total willingness and ability script items, suggesting that even though respondents have predominantly expert scripts these are not always significantly linked to selfefficacy.

\section{DISCUSSION}

\section{Interpretation}

In examination of hypothesis 1 , moderate support was found (55\% of total cues) for respondents having completed a venture creation decision to consistently recognise and select statements that evidence expert entrepreneurial scripts. Given the theory advanced in support of this hypothesis - willingness and ability scripts are thought to be associated with new venture formation (Busenitz \& Lau, 1996; Krueger, Reilly \& Carsrud, 2000) - the results generally affirm the selection of expert cues by respondents. The results are generally conservative, and there seems to be limited influence of expert willingness and ability scripts on the venture decision. Similar to other researchers who have expanded the emerging cognitive perspective on entrepreneurship to argue that scripts explain similarities in venture decision-making across cultures (Mitchell et al., 2000, p. 976), this paper suggests that there may exist a global, universal entrepreneurial mindset; in other words, entrepreneurs think in similar ways and possess similar patterns of cognitive structure, regardless of country of origin.

Partial support was found for hypothesis 2, where willingness and ability scripts were expected to be positively associated with entrepreneurial motivation (self-efficacy). Several willingness and ability cognition scripts were associated with self-efficacy, although to a limited extent. Evidence of the previously described general cognitive processes - arrangements (feasibility), willingness (propensity to act) and ability (desirability) - have been found in the testing of intentional and motivational models (Mitchell, Busenitz et al., 2002, p. 990).

\section{Conclusions}

More positive associations between cognitions and motivation were expected. The capability for self-motivation and purposive action is rooted in cognitive activity. In cognitive motivation people motivate themselves and guide their actions anticipatory through the exercise of forethought (Bandura, 1997, p. 34). Perhaps the linking of deep cognitive structures to more surface-level phenomena - such as self-efficacy - was curtailed due to the limited development of cognitive scripts, as evident in hypothesis 1.

Notwithstanding the modest results, the research approach taken in this paper should not be interpreted as a reductive fragmentary one where the emphasis was primarily on unobservable cognitive mechanisms. Mental events are brain activities but physicality does not imply reduction of psychology to biology (Bandura, 2001, p. 35). As conceptualised, the inner workings of the mind in cognitive processing are best studied when they are related to a more surface phenomena such as motivation. Cognitions and motivation operate in concert with other determinants to govern human thought, motivation and action (Bandura, 1997, p. 35). Even though a person may have relevant skills, such skills depend on the person's thoughts; it is for this reason that different people with similar skills, 
or the same person on different occasions, may perform differently. Moreover demographic characteristics indirectly relate to entrepreneurial decision-making, where having entrepreneurial parents, friends or relatives was found to be associated with several of the entrepreneurial cognitions.

\section{Limitations}

The modest results could further be interpreted in light of the study's limitations since the study is limited by the early stage of theoretical development in entrepreneurial cognitions as well as by the reduction in statistical power through the use of categorical variables in the measurement and analysis.

\section{Recommendations}

Having contributed to the cognitive perspective, the results of this study have implications for social cognition theorists and entrepreneurship researchers. By relying on established cognitive theory, which has greatly improved people's understanding of virtually every aspect of human behaviour to which it has been applied, researchers are encouraged to further explore this cognitions-based entrepreneurship perspective. Within entrepreneurship research there is a need to add to existing theory and argue for the importance of belief/cognitive issues in entrepreneurship (Krueger, Reilly \& Carsrud, 2000, p. 428). The findings also have relevance in the substantive domain, where with a great deal of resources supporting entrepreneurial activity within South Africa (Orford, Herrington \& Wood, 2004, p. 4), national policy makers who are trying to encourage entrepreneurial behaviour should support venture creation decisions that are made in accordance with willingness and ability scripts, as delineated in this study. Entrepreneurial skills training programs could focus on how individuals take recourse to their cognitive scripts as they interact with environmental opportunities and constraints and thus develop very different sets of venture decisions and growth intentions (Dutta \& Thornhill, 2007, p. 3).

\section{Suggestions for further research}

Researchers are encouraged to expand on this study by building additional conceptual bridges between the extant literature on human cognitions and entrepreneurship research.

\section{REFERENCES}

Amanjee, B., Crous, F. \& Crafford, A. (2006). Towards validating a framework of adaptive schemata for entrepreneurial success. SA Journal of Industrial Psychology, 32(3), 26-34.

Bandura, A. (1986). Social foundations of thought and action: A social cognitive theory. Englewood Cliffs, N.J: Prentice Hall.

Bandura, A. (1997). Self-efficacy: The exercise of control. New York: W.H. Freeman and Company.

Bandura, A. (2001). Social cognitive theory: An agentic perspective. Annual Review of Psychology, Winter, 1-36.

Baron, R.A. \& Ward, T.B. (2004). Expanding entrepreneurial cognitions toolbox: Potential contributions from the field of cognitive science. Entrepreneurship Theory and Practice, Winter, 553-573.

Baron, R.A. (2004). The cognitive perspective: A valuable too for answering entrepreneurship's basic "why" questions. Journal of Business Venturing, 19(2), 221-239.

Boyd, N.G. \& Vozikis, G.S. (1994). The influence of self-efficacy on the development of entrepreneurial intentions and actions. Entrepreneurship Theory and Practice, 18(4), 63-78.

Busenitz, L.W. \& Lau, C.M. (1996). A cross-cultural cognitive model of new venture creation. Entrepreneurship Theory and Practice, 20(4), 25-39.

Chen, G, Gully, M.S. \& Eden, D. (2001). Validation of a new general self-efficacy scale. Organizational Research Methods, 4, 62-83.

Cooper, D.R. \& Schindler, P.S. (2001). Business research methods. (7th Ed.). Singapore: McGraw-Hill.
Corbett, A.C. \& Hmieleski, K.M. (2007). The conflicting cognitions of corporate entrepreneurs. Entrepreneurship Theory and Practice, Winter, 103-121.

Davidsson, P. \& Wiklund, J. (1997). Values, beliefs and regional variations in new firm formation rates. Journal of Economic Psychology, 18(2), 179-199.

Douglas, E.J. \& Shepherd, D.A. (2002). Self-employment as a career choicer: Attitudes, entrepreneurial intentions and utility maximization. Entrepreneurship Theory and Practice, 26, 81-90.

Dutta, D.K. \& Thornhill, S. (2007). The evolution of growth intentions: Toward a cognition-based model. Journal of Business Venturing, 23(3), 307-332.

Gaglio, C.M. (2004). The role of mental simulations and counterfactual thinking in the opportunity identification process. Entrepreneurship Theory and Practice, 28(6), 533-553.

Gist, M.E. \& Mitchell, T.R. (1992). Self-efficacy: A theoretical analysis of its determinants and malleability. Academy of Management Review, 17(2), 183-212.

Hisrich, R.D. (2000). Entrepreneurial dimensions: The relationship of individual, venture, and environmental factors to success. Entrepreneurship Theory and Practice, 24(4), 79-90.

Krueger, N.F. \& Brazael, D.V. (1994). Entrepreneurial potential and potential entrepreneurs. Entrepreneurship Theory and Practice, 18(3), 91-105.

Krueger, N.F. (1993). The impact of prior entrepreneurial exposure on perceptions of new venture feasibility and desirability. Entrepreneurship Theory and Practice, 18(1), 5-23.

Krueger, N.F. (2000). The cognitions infrastructure of opportunity emergence. Entrepreneurship Theory and Practice, $24,5-24$.

Krueger, N.F. (2007). What lies beneath? The experiential essence of entrepreneurial thinking. Entrepreneurship Theory and Practice, Winter, 123-138.

Krueger, N.F., Reilly, M.D. \& Carsrud, A.L. (2000). Competing models of entrepreneurial intentions. Journal of Business Venturing, 15(5/6), 411-432.

Markman, G.D., Balkin, D.B. \& Baron, R.A. (2002). Inventors and new venture formation: The effects of general self-efficacy and regretful thinking. Entrepreneurship Theory and Practice, Winter, $149-165$.

McClelland, D.C. (1961). The achieving society. New York: Free Press.

Minniti, M. \& Bygrave, W.D. (2003). National entrepreneurship assessment United States of America. GEM Global Entrepreneurship Monitor, Babson College, 1-42.

Mitchell, R.K., Busenitz, L., Bird, B., Gaglio, C.M., McMullen, J.S., Morse, E.A. \& Smith, J.B. (2007). The central question in entrepreneurial cognition research 2007. Entrepreneurship Theory and Practice, Winter, 1-27.

Mitchell, R.K., Busenitz, L., Lant, T., Mc Dougall, P.P., Morse, E.A. \& Smith, J.B. (2002). Toward a theory of entrepreneurial cognition: Rethinking the people side of entrepreneurship research. Entrepreneurship Theory and Practice, Winter, 93104.

Mitchell, R.K., Smith, J.B., Morse, E.A., Seawright, W.K., Peredo, A.M. \& Mckenzie, B. (2002). Are entrepreneurial cognitions universal? Assessing entrepreneurial cognitions across cultures. Entrepreneurship Theory and Practice, Summer, 9-32.

Mitchell, R.K., Smith, J.B., Seawright, W.K. \& Morse, E.A. (2000). Cross-cultural cognitions and the venture creation decision. Academy of Management Journal, 43(5), 974-993.

Neisser, U. (1967). Cognitive psychology. New York: Appleton.

Orford, J., Herrington, M. \& Wood, E. (2004). South African global entrepreneurship monitor report. Graduate School of Business, Cape Town, 1-56.

Read, S.J. (1987). Constructing casual scenarios: A knowledge structure approach to causal reasoning. Journal of Personality and Social Psychology, 52, 288-302.

Urban, B. (2006). ESE in a multicultural society: Measures and differences. SA Journal of Industrial Psychology, 32(1), 2-10. 